\title{
MÃES QUE PERDERAM FILHOS ADULTOS: UM GRUPO FOCAL
}

DOI: 10.22289/2446-922X.V8N1A9

\author{
Eduarda Camila Saft ${ }^{1}$ \\ Flávia Michelle Pereira Albuquerque
}

\section{RESUMO}

A morte apesar de fazer parte do processo de desenvolvimento humano, como último estágio, ainda é pouco comentada nos círculos sociais, pois está associada a dor e sofrimento, pois caracteriza o rompimento de vínculo afetivo, além de nos lembrar de nossa própria finitude. Quando uma mãe perde um filho, depara-se com uma dor dilacerante, como se uma parte desta mãe tivesse morrido junto de seu filho, dor tamanha que faltam termos adequados para defini-la. A presente pesquisa é qualitativa, exploratória, descritiva e de campo. A coleta de dados foi realizada através de um grupo focal realizado com quatro mães que perderam seus filhos na fase adulta, que já faleceram há pelo menos cinco anos, mulheres estas que residem em um município do noroeste do estado do Rio Grande do Sul. A análise e interpretação dos dados foi com análise de conteúdo. A relevância deste estudo reside na possibilidade de produzir reflexões sobre o luto materno possibilitando o planejamento de ações que envolvam os enlutados, familiares e comunidade promovendo saúde, ressignificação de sentimentos e completude do sujeito.

Palavras-chave: Morte; Luto; Mães; Filho; Dor.

\section{MOTHERS WHO HAVE LOST ADULT CHILDREN: A FOCUS GROUP}

\section{ABSTRACT}

Death, although being part of human development, in its last stage, it is still not so debated in social circles, being associated to pain and suffering, because it characterizes the breaking of affective bonds, besides making us remember of our own finitude. When a mother loses her son, she faces a lacerating pain, as if one part of her has died together with her son, it lacks words to define such pain. The present is a qualitative, exploratory, descriptive and field research. The data collection was conducted through a focal group with four mothers who lost their children during adult stage, who have passed away at least five years ago, women who reside in a municipality in the northeast of Rio Grande do Sul state. The analysis and interpretation of data was carried out with content analysis. The relevance of this study resides in the possibility of producing reflections about maternal mourning allowing planning of actions which involve the mourners, family and community promoting health, resignification of feelings and completeness of the individual.

Keywords: Death; Mourning; Mothers; Son; Pain.

\footnotetext{
${ }^{1}$ Endereço eletrônico de contato: eduardacsaft@gmail.com

Recebido em 07/12/2021. Aprovado pelo conselho editorial para publicação em 17/01/2022.
}

Rev. Psicol Saúde e Debate. Jan., 2022:8(1): 138-159. 


\section{MADRES QUE HAN PERDIDO HIJOS ADULTOS: UN GRUPO FOCAL}

\section{RESUMEN}

La muerte, a pesar de ser parte del proceso de desarrollo humano, como última etapa, es todavía poco comentada en los círculos sociales, estando asociada al dolor y al sufrimiento, ya que caracteriza la ruptura del vínculo afectivo, además de recordarnos el nuestro finitud. Cuando una madre pierde un hijo, se enfrenta a un dolor insoportable, como si una parte de esta madre hubiera muerto con su hijo, un dolor tal que no hay términos adecuados para definirlo. Esta investigación es cualitativa, exploratoria, descriptiva y de campo. La recolección de datos se realizó a través de un grupo focal realizado con cuatro madres que perdieron a sus hijos en la edad adulta, quienes han fallecido por al menos cinco años, mujeres que viven en un municipio del noroeste del estado de Rio Grande do Sul. El análisis e interpretación de los datos se realizó con análisis de contenido. La relevancia de este estudio radica en la posibilidad de producir reflexiones sobre el duelo materno, posibilitando la planificación de acciones que involucren al doliente, la familia y la comunidad, promoviendo la salud, la resignificación de los sentimientos y la integridad del sujeto.

Palabras clave: Muerte; Luto; Madres; Hijo; Dolor.

\section{Introdução}

A maternidade é um evento que altera a vida da mulher, modificando o próprio corpo, as questões subjetivas e, inclusive, o estilo de vida, adaptando-se a este evento: a chegada de um filho. Como ressalta Augras (1977, p. 251), "não são mudanças fisiológicas apenas, mas também psicossociais - a gravidez provoca mudança de identidade e nova definição de papéis". Ao falarmos em vínculo materno, a psicanálise enfatiza que, o vínculo é gerado antes mesmo da concepção do bebê, quando o filho passa a ser idealizado. Com o nascimento da criança o vínculo materno é concretizado e alimentado ao longo de todo o desenvolvimento do filho (Rolón, 2010).

Quando o vínculo é rompido, por morte do filho na fase adulta, ocorre a desestruturação da mãe e por mais difícil que seja, a mãe precisa desenvolver estratégias para enfrentar este sofrimento, mas há muitas questões que colaboram para intensificar esse sofrimento, levando em conta que culturalmente, a morte ainda não é encarada como parte do ciclo vital. Quando ocorre a morte do filho, a ruptura no curso natural da vida, em uma ideia de que os mais velhos deveriam morrer primeiro, pode gerar grande desestabilização nos sentimentos e na vida diária dos enlutados, pois além da dor da perda do filho, há o contato com a impotência humana diante da morte (Vitekpasa \& Stelmachuk, 2015).

Quando ocorre a morte do filho em fase adulta, com todo o sofrimento que as mães vivenciam, podem surgir fantasias de culpabilidade, como afirma Oliveira e Lopes (2008, p. 220) "a morte de um filho pode representar a impotência do amor dos pais para evitar esse evento final, podendo colocar em dúvida a qualidade desse amor, como se esse tivesse fracassado. Eles podem sentir-se culpados por sobreviverem ao filho". Com a morte do filho, a dor e sofrimento 
experienciados provocam significativas mudanças na vida da mãe, que transformam a própria identidade, suas questões, seu plano de vida até parte de sua história. Para uma mãe, "a morte de um filho que viveu no meio da família, que se tornou uma pessoa, grande ou pequena, conhecida, a perda lamentada não inclui somente as esperanças para o futuro, mas também o passado compartilhado" (Viorst, 1988, p. 263).

Apesar do crescente número de estudos sobre o luto, a temática de enfrentamento da dor por mães que perderam filhos em fase adulta, é escassa na literatura. Além deste fator, os estudos sobre luto durante a graduação e a proximidade da pesquisadora com o tema sobre mães que perderam filhos em idade adulta, motivaram esta pesquisa, a qual se justifica enquanto possibilidade de contribuir para melhor compreensão da experiência de mães que perderam filhos adultos e de estratégias de enfrentamento de sua dor, a qual não possui um termo capaz de defini-la - o luto pela morte de um filho.

Considerando a necessidade de estabelecer um olhar às mães que perderam seus filhos na fase adulta, indagou-se "Como mães que perderam filhos em fase adulta, enfrentam a dor de um luto não nominado? ", tendo como objetivo identificar os processos psicossociais que auxiliam mães que perderam filhos adultos a enfrentarem a dor de um sofrimento não nominado, através de um grupo focal. Esta pesquisa é qualitativa, exploratória, descritiva e de campo. A coleta de dados foi realizada através de um grupo focal realizado com quatro mães que perderam seus filhos na fase adulta, mulheres estas que residem em um município do noroeste do estado do Rio Grande do Sul. A análise e interpretação dos dados foi com análise de conteúdo. A relevância deste estudo reside na possibilidade de produzir reflexões sobre o luto materno possibilitando o planejamento de ações que envolvam os enlutados, familiares e comunidade promovendo saúde, ressignificação de sentimentos e completude do sujeito.

\section{Materiais e Métodos}

A presente pesquisa classifica-se como qualitativa, exploratória, descritiva, bibliográfica e de campo.

Quanto a abordagem a pesquisa é qualitativa, que, para Sampieri, Collado e Lucio (2013) tem como foco compreender e aprofundar os fenômenos através da perspectiva dos participantes sobre os fenômenos que os rodeiam, aprofundar suas experiências, pontos de vista, opiniões e significados, ou seja, a forma como os participantes percebem subjetivamente sua realidade. Entretanto, na pesquisa qualitativa, conforme Gallert, Loureiro, Silva e Souza (2011), não é o tamanho do grupo que define os procedimentos de construção do conhecimento, mas as exigências de informação quanto ao modelo em construção que a caracterizam. Desta forma se deu a escolha pelo tipo de pesquisa, por permitir que os grupos pequenos tenham a mesma validade, pois foram 
investigadas quatro mães que perderam seus filhos em idades entre vinte a trinta anos, há pelo menos cinco anos.

O método qualitativo permite compreender o participante em suas particularidades, suas características psicossociais. Enquanto o modelo descritivo, permite relatar as características, que forem pertinentes ao estudo, da população enfatizada: mães que perderam filhos adultos (Creswell, 2007).

Quanto aos objetivos, esta pesquisa é descritiva e exploratória, pois visa proporcionar maior familiaridade com o problema com vistas a torná-lo explícito e a descrever as características de uma determinada população (mães que perderam seus filhos na fase adulta da vida). Quanto aos procedimentos técnicos utilizamos a pesquisa bibliográfica e a pesquisa de campo. Na pesquisa bibliográfica, o estudo sistematizado e desenvolvido tem como base o material publicado em livros, artigos científicos constantes em revistas indexadas e redes eletrônicas, que foram utilizados amplamente pela pesquisadora. Esta levou em consideração autores de renome no tema, bem como artigos científicos e trabalhos acadêmicos realizados em instituições de estudo no Brasil. $\mathrm{Na}$ pesquisa de campo realizamos o grupo focal que aconteceu no dia 8 de junho de 2021, com duração de aproximadamente duas horas no local.

Após a aprovação pelo Comitê de Ética em Pesquisa, através do CAAE $\mathrm{n}^{\text {a }}$ 42958020.7.0000.5342 entramos em contato com a rede municipal de saúde que nos informou sobre possíveis participantes para esta pesquisa. Essas mulheres foram convidadas a participarem dessa pesquisa e assinaram o Termo de Consentimento Livre e Esclarecido (TCLE) e tiveram todas as suas dúvidas referentes à pesquisa sanadas pela pesquisadora. Os dados para realização da pesquisa foram colhidos em um único momento, em forma de grupo focal com a participação de quatro mulheres que perderam seus filhos em idades entre 20 a 30 anos de idade.

A pesquisa foi realizada a partir de uma investigação analítica e descritiva com abordagem qualitativa e foi utilizada para análise dos dados a técnica de Análise de Conteúdo, que nos permitiu compreender criticamente o sentido das falas e descobrir elementos ocultos, indo além das aparências do que está sendo comunicado, sempre levando em consideração as respostas expressas nos questionários. A análise de conteúdo é uma técnica de pesquisa que trabalha com as palavras e permite de forma prática e objetiva produzir inferências do conteúdo da comunicação de um texto replicável ao seu contexto social. Gallert et al (2011) afirmam que é cada vez mais pertinente e necessária à compreensão da realidade, aqui entendida pelo viés da perspectiva histórica, e a subjetividade vem ocupando lugar na reflexão da ciência enquanto processo de construção do conhecimento. A análise foi realizada com base no grupo focal realizado com as mães público-alvo dessa pesquisa.

Para fins deste estudo as participantes foram identificadas por nome de flores, para preservar sua identidade e como simbologia do feminino. As flores estão repletas de simbologia e 
podem simbolizar nova vida e vitória sobre a morte, temas existentes e intrínsecos ao sofrimento psíquico vivenciado por essas mulheres.

Quadro 1 - Descrição das participantes

\begin{tabular}{|l|l|l|l|l|}
\hline $\begin{array}{l}\text { Nome fictício da } \\
\text { Participante }\end{array}$ & Bromélia $^{1}$ & Margarida & Crisântemo & Ciclame \\
\hline Estado Civil & Casada & Casada & $\begin{array}{l}\text { divorciada após } \\
\text { a morte do filho }\end{array}$ & $\begin{array}{l}\text { divorciada antes } \\
\text { da morte da } \\
\text { filha }\end{array}$ \\
\hline Profissão & $\begin{array}{l}\text { professora } \\
\text { aposentada }\end{array}$ & $\begin{array}{l}\text { agricultora } \\
\text { aposentada }\end{array}$ & $\begin{array}{l}\text { agricultora } \\
\text { aposentada }\end{array}$ & $\begin{array}{l}\text { doméstica } \\
\text { recebendo } \\
\text { auxílio saúde }\end{array}$ \\
\hline Filhos & 03 & 01 & 01 & 02 \\
\hline $\begin{array}{l}\text { Idade em que o } \\
\text { filho(a) faleceu }\end{array}$ & 20 & 27 & 22 & 22 \\
\hline $\begin{array}{l}\text { Tempo de } \\
\text { falecimento do } \\
\text { filho(a) }\end{array}$ & 12 anos & $\begin{array}{l}10 \text { anos e } 8 \\
\text { meses }\end{array}$ & 19 anos & 5 anos 6 meses \\
\hline $\begin{array}{l}\text { Causa da morte } \\
\text { do filho (a) }\end{array}$ & suicídio & $\begin{array}{l}\text { acidente de } \\
\text { trânsito }\end{array}$ & $\begin{array}{l}\text { acidente de } \\
\text { trânsito }\end{array}$ & homicídio \\
\hline
\end{tabular}

\section{Discussão e Resultados}

"A dor vai curar essas lástimas O soro tem gosto de lágrimas As flores têm cheiro de morte A dor vai fechar esses cortes

Flores, Flores As flores de plástico não morrem"

\footnotetext{
${ }^{1}$ Significado: resistência, inspiração

${ }^{2}$ Significado: resistência, amor leal, simplicidade

${ }^{3}$ Significado: despedida de verão, amor acabado

${ }^{4}$ Significado: sugerem o adeus
}

Rev. Psicol Saúde e Debate. Jan., 2022:8(1): 138-159. 


\subsection{Caracterizando o luto}

Para que possamos compreender a intensidade da dor e sofrimento narrado pelas participantes desta pesquisa, precisamos compreender o luto em sua totalidade. Para isso, utilizaremos de autores importantes da área para auxiliar a denominar a dor do luto, suas fases e tarefas, sem deixar de considerar a particularidade de cada indivíduo enlutado, neste caso, mães que perderam filhos na fase adulta, ressaltando ainda, o vínculo envolvido entre mãe e filho, que pode influenciar para que o luto seja mais intenso e dure por mais tempo, como é verificado pelas narrativas das participantes da pesquisa, como veremos adiante.

Segundo Freud (2006), o luto é a reação desencadeada pela perda de um ente querido, a perda real do objeto amado, que pode trazer a sensação de que o mundo se torna pobre e vazio. Freud chama de "trabalho do luto" o movimento de retirar a libido investida na ligação com o ente falecido, sendo esta uma condição dolorosa a qual o enlutado precisa dar conta para adequar-se com a realidade.

Para Kovács (1992) o luto é o sentimento de dor e sofrimento de diferente intensidade, desencadeado pelo rompimento do vínculo afetivo com um ente querido que faleceu. Relacionando com a morte de um filho, o sentimento de dor da mãe, pode ser descrito como intensa, considerando o vínculo de cuidado e proteção que é rompido.

Para compreendermos o impacto de uma perda, Worden (2013) enfatiza que devemos compreender a Teoria do Apego, desenvolvida e discutida pelo psiquiatra britânico John Bowlby em 1977, o qual definiu uma tendência nos seres humanos em criar fortes laços afetivos com os outros, laços que vão além da satisfação biológica (alimentação, sexualidade), mas que sugerem uma necessidade de segurança e proteção. Criar laços com pessoas significativas, segundo o autor, é um comportamento normal, assim esses comportamentos de apego tem um valor de sobrevivência. Se o objetivo do apego é manter o laço afetivo, as situações que colocam em risco esse laço, despertam reações que podem ser intensas e variadas. Logo, a perda deste laço, pode trazer a sensação de dificuldade de sobrevivência.

De acordo com Bowlby (2004), o luto pode ser caracterizado em quatro fases que não são bem delineadas e podendo apresentar oscilações, são elas:

Fase do entorpecimento: reação imediata após a notícia da morte do ente querido, pode durar horas ou semanas. O indivíduo sente-se chocado, incapaz de aceitar a notícia, podendo sofrer ataques de pânico, explosões de raiva ou até sentir-se em união com o morto.

Fase de anseio e busca da figura perdida: raiva: ocorre em horas ou dias após a perda, quando o indivíduo começa a registrar a perda como real, são comuns desânimo intenso, inquietação, insônia, aflição e lembranças do morto que frequentemente são despertadas. 
Fase de desorganização e desespero e fase de reorganização: de maneira gradual o indivíduo passa a compreender a perda como real e irreversível, que implica em uma experiência de diversas emoções como o abatimento e a raiva, que são necessárias ao processo de compreensão. Também, desta forma, o indivíduo vai precisar reorganizar sua vida, desempenhando algumas tarefas do falecido, retomar sua vida conjugal, social e afetiva, adaptando- se a solidão do vínculo perdido.

O autor Worden (2013), discorda com a denominação que Bowlby utiliza em considerar o luto em fases, pois, para Worden, as nomenclaturas de fases despertam uma ideia de uma situação passiva como algo que o enlutado deve ultrapassar. Por isso, Worden (2013) traz a nominação de tarefas do luto, pois representam algo que o enlutado deve encarar. Desta forma, Worden (2013) apresenta as quatro tarefas do luto:

Tarefa I - aceitar a realidade da perda: mesmo existindo a sensação de que a morte não aconteceu, o enlutado precisa aceitar essa realidade e perceber que o reencontro, nesta vida, é impossível. Esta tarefa é difícil e pode ser muito negligenciada, ver pessoas na rua com semelhança física ao morto, trazendo a sensação de ser ele, é uma experiência típica de quem ainda não aceitou a perda, além de vários outros comportamentos que neguem o significado da perda, como guardar os pertences e manter as atividades da pessoa falecida esperando que ela retorne, ou então diminuir a importância do vínculo com a pessoa perdida para se proteger do sofrimento.

Tarefa II- processar a dor do luto: esta tarefa refere-se a encarar a dor e o sofrimento de perder um ente querido. É comum as pessoas fugirem desta realidade tentando se proteger do sofrimento das mais variadas formas (mudanças, viagens) porém em algum momento esta realidade vai precisar ser encarada. Devido a fuga de processar o luto podem se originar sintomas psicossomáticos dos mais variados aspectos. Também nesta etapa, a sociedade pode se demonstrar desagradável com os sentimentos do enlutado, justamente por ser um processo dolorido.

Tarefa III- ajustar-se ao mundo sem a pessoa morta: o enlutado precisa ajustar-se em vários aspectos como: ajustes externos: se relaciona aos ajustes do ambiente, conviver com a falta da pessoa falecida e ainda precisar desenvolver habilidades para desempenhar as tarefas do falecido; ajustes internos: além de se adaptar aos novos papéis que lhe cabem, o enlutado tem alteração da própria identidade, autoestima e senso de eficácia, de acordo com a intensidade do vínculo perdido; ajustes espirituais: não é incomum o enluto sentir que perdeu o sentido da vida e precisar encontrar uma forma de retomar sua vida, em alguns casos a morte desafia algumas das crenças básicas do indivíduo e em outros pode reafirmar essas crenças, dependendo do contexto.

Tarefa IV- encontrar uma conexão duradoura com a pessoa morta em meio ao início de uma nova vida: manter laços com a pessoa falecida, permitindo que o enlutado permaneça conectado a ela, sem prejudicar a forma com que retome sua vida. 
O processo de luto ocorre em um determinado tempo, o qual se considera saudável, ou seja, existe uma fase de adaptação a perda do ente falecido o qual não é um processo rápido e contínuo, mas sim, um processo que exige a ressignificação de muitos aspectos da vida do ente enlutado. Neste sentido, entendemos que as tarefas do luto são caracterizadas em fases para fins de compreensão, mas o luto é um processo contínuo não vivenciado em etapas, mas sim com características determinantes do processo de luto que se entrelaçam e acontecem simultaneamente. Como ressalta Michel e Freitas (2019, p. 03), "O luto não seria, portanto, um processo linear, determinado por estágios ou fases iniciais e finais, mas se trata de uma nova condição existencial na qual é lançado aquele que perdeu alguém que lhe é significativo".

Sabemos que o modo de encarar a morte e de vivenciar o processo de luto, é singular e sofre influências das características pessoais do indivíduo enlutado, como os traços de personalidade e as situações as quais já vivenciara, mas também influências do meio social e cultural, como ressalta Ramos (2016, p.03):

A definição de "Processo de Luto" é bastante complexa na medida em que cada pessoa o vivencia de forma diferente, mediante as culturas, o meio em que está inserida e o próprio contexto da perda também influencia a forma como a pessoa vai encarar o luto.

Ressaltando a particularidade de cada indivíduo em seu processo de luto, que apesar de se apresentar de uma forma semelhante, este processo pode ser vivenciado de diferentes perspectivas por cada pessoa enlutada, de acordo com suas experiências pessoais. Worden (2013, p. XVI) enfatiza que "Apesar das tarefas do luto serem aplicadas a todas as perdas por morte, a forma como cada pessoa realiza e adapta-se a essas tarefas pode ser muito variável. " Assim, considerar as mesmas características para abordar o processo de luto de diferentes pessoas, é muito restritivo, eis a importância de considerar a particularidade e subjetividade de cada indivíduo enlutado.

De acordo com o Manual Diagnóstico e Estatístico de Transtornos Mentais o luto sem complicações como uma reação normal à morte de um ente querido, onde que os sintomas se assemelham aos do transtorno depressivo maior, havendo alterações de acordo com o contexto cultural no qual o indivíduo em sofrimento está inserido (Dsm-v, 2014). Este mesmo Manual apresenta o Transtorno do Luto Complexo Persistente, onde os sintomas relacionados à perturbação social e de identidade e sofrimento reativo à morte persistem por doze meses em adultos enlutados e até seis meses em crianças, causando sofrimento clinicamente significativo (Dsm-v, 2014). O que pode verificar-se em alguns dos relatos das mulheres entrevistadas, sobre seus processos de luto.

\subsection{Narrando a perda}

Rev. Psicol Saúde e Debate. Jan., 2022:8(1): 138-159. 
"Mesmo sabendo que um dia a vida acaba, nós nunca estamos preparados para perder alguém" (Nicholas Sparks)

Após a apresentação inicial e esclarecimento sobre o objetivo da pesquisa, bem como a funcionalidade desta, as mães participantes da pesquisa começaram a relatar sobre a perda de seu filho bem como demais temáticas atinentes ao objetivo da pesquisa. As narrativas ocorrem de forma a qual cada participante se sentiu confortável, relatando situações que julgavam pertinentes serem compartilhadas ao grupo. Evidenciando assim que, falar abertamente sobre a morte do filho mostrase um método eficaz, ao compartilhar seus sentimentos e anseios com pessoas que também já vivenciaram esta situação (Soares, Kuchla, Mazza, Soares, Ferras, \& Mattei, 2020).

A participante Bromélia se sentiu à vontade para iniciar e relatou ser mãe de três filhos, sendo o do meio falecido há doze anos. Na época de sua morte tinha vinte anos de idade. No início de seu relato apresentou a causa da morte do filho como uma queda do telhado, em outro momento, quando questionada pela participante Ciclame sobre o garoto ter sofrido com um episódio de vertigem, respondeu: "Não, ele se jogou de lá. Ele planejou, no domingo ele olhou para o telhado e fez assim (movimento positivo com a cabeça) e eu disse: filho tem alguma coisa, você enxerga alguma coisa? É que ele tinha esquizofrenia e pensei que ele enxergava alguma coisa lá em cima e não me contava". Após alguns dias, o menino teve um desentendimento com o pai e cometeu o ato, relata a mãe. Neste relato, podemos perceber que houve uma certa resistência em falar sobre o suicídio do filho, como ressaltam Fukumitsu e Kovács (2016), expressar que um ente querido cometeu suicídio pode gerar vergonha, assim o isolamento e o silêncio em relação ao suicídio de alguém próximo pode ser desencadeado pelo sentimento de evitar possíveis constrangimentos.

Margarida, outra participante do grupo, trouxe o relato de como perdeu sua única filha em uma manhã, a caminho do trabalho, a filha sofreu um acidente grave, sendo fatal e que na época a jovem tinha vinte e sete anos de idade, e desde então já se passaram dez anos e oito meses desta trágica perda. Em seu relato, Margarida demonstrou sentir revolta pela situação: "Podem chamar de acidente, mas na verdade não é acidente, ele (outro motorista) matou ela, não foi um acidente na verdade. Olha, eram 7:20 da manhã, o outro motorista estava dirigindo a trinta e seis horas, veio dormindo em uma curva na contramão, isso não é acidente, para mim, não é acidente! ". Worden (2013, p.06), nos fala sobre a raiva do indivíduo enlutado, onde:

Com frequência, a pessoa pode lidar com isso de maneiras menos eficazes, uma das quais é o deslocamento ou o direcionamento a outra pessoa, muitas vezes a responsabilizando pela morte ocorrida. A linha de raciocínio é que, se alguém pode ser culpado, então a pessoa é responsável e, por conseguinte, a perda poderia ter sido evitada. 
A participante Crisântemo sentiu-se à vontade para trazer seu relato, trouxe ter sessenta anos de idade, ser agricultora aposentada e relatou ter perdido seu único filho há dezenove anos, na época, este estava com vinte e dois anos de idade. Contou que o rapaz estudava e trabalhava, sendo que durante o percurso de volta para casa, o veículo que dirigia saiu da estrada e o filho faleceu. Que não houve o envolvimento de outros veículos. Crisântemo, em sua fala, trouxe um sentimento de desesperança, relatou "agora tô aí, tenho que carregar a cruz que Deus me deu, não é fácil. Quando eu escuto um falecimento no rádio, eu sempre penso: "pobre desta mãe" "Deus quando vai parar isso? De morrer jovens?"

Ciclame relatou ter cinquenta e oito anos de idade, mãe de dois filhos, sendo que a sua filha foi assassinada pela companheira, há cinco anos e meio, sua filha na época estava com vinte e dois anos de idade. Narrou que a filha morava em uma cidade maior, para estudar. Nesta cidade conheceu uma garota a qual moraram juntas e após um desentendimento, a garota a feriu com uma arma branca (faca), tendo deferido diversas facadas contra a jovem que culminou com sua morte. Em seu relato, Ciclame trouxe uma riqueza de detalhes sobre o ocorrido no ato violento que tirou a vida de sua filha, ao mesmo tempo que trazia seu relato para o grupo, "banhava-se" em lágrimas, demonstrando o quanto a dor de ter perdido a filha em um ato violento é profunda, constando ainda que o sentimento de injustiça lhe é perturbador e lhe acompanha diariamente.

Apesar de ser um grupo focal sobre um tema específico, os relatos demonstram o quanto cada situação provoca sentimentos diversos e vivências de dor, desolação, tristeza e angústia em cada pessoa. A subjetividade de cada relato, de vivência, encarada por cada uma destas mães com um olhar diferente, mas com um sentimento de vazio, o qual é relatado e vivenciado por cada uma destas mães, como a própria participante Bromélia comentou: "cada uma aqui, teve uma vivência diferente, uma história diferente, o sentimento trazido é o mesmo, que todas perderam um pedaço de si! " Esta expressão demonstra que não foi interrompida só a ligação com o filho que morreu, mas como também, levada com ele, o modo daquela mãe existir que se mostrava na singularidade da relação com aquele filho, sentindo assim, que um pedaço de si morreu junto com o filho (Freitas \& Michel, 2014).

\subsection{Sentimentos desencadeados com a perda do filho}

"O sofrimento precisa ser superado, e o único meio de superá-lo é suportando-o" (Carl Jung)

Em cada trecho revelado durante o grupo focal surgiram relatos de sentimentos e emoções profundas, desencadeados pela perda do filho. Alguns destes sentimentos enfatizaram a particularidade de cada relato, outras puderam ser compartilhados por estas mães, sempre sendo 
demonstrado sentimento de uma dor intensa, entretanto sem conseguirmos localizar uma nomenclatura única capaz de definir sua totalidade.

Em um momento de fala da participante Bromélia, revelou "perder um filho é perder um pedaço da gente, só sei que nunca mais será igual. E se fosse diferente? E o porquê desta forma?

" Esse sentimento de culpa (quanto ao suicídio, quanto a ter ocorrido a morte desta forma) foi paralisante. Este sentimento torna o luto ainda mais difícil de ser elaborado, pois o enlutado pode pensar que deveria ter feito algo para evitar a morte, além de carregar o estigma sobre o suicídio. (Fukumitsu \& Kovács, 2016).

A morte de um filho é um acontecimento desestruturante na vida dos pais, entendendo-se que a ordem natural da vida é invertida, pois conforme Menezes e Marciano (2019) os mais velhos que deveriam falecer primeiro, gerando assim, sentimentos de dor e sofrimentos intensos, além da impotência e frustração referente a perda do filho situação essa, que foi expressada por Ciclame " $A$ gente se sente impotente, a gente protege e protege os filhos e depois acontece isso ainda (a morte) ".

Sabe-se que o vínculo materno é construído desde o planejamento do bebê sendo "alimentado" em todo o processo de desenvolvimento deste filho. Quando ocorre a ruptura desse vínculo, pela morte do filho, inicia-se um processo, que pode despertar um abalo emocional intenso e alterar questões essenciais da personalidade e de relacionamentos sociais, visto que esse processo de luto, apesar de ser reconhecido como sofrimento intenso, não é compreendido em sua totalidade. As mães que passam por experiências de sofrimento, neste sentido, vivenciam um processo de desorganização do qual precisam enfrentar.

Para os indivíduos enlutados, segundo Gonçalves (2014), a forma como ocorreu a morte do ente querido, altera a experiência de elaboração do luto. Quando a morte do ente querido, neste caso, do filho, ocorre sem aviso, ou seja, de forma inesperada, como é o caso das participantes deste estudo, onde todas perderam seus filhos subitamente, determinante que pode influenciar na intensidade deste processo e na durabilidade dos sintomas. Worden (2013), nos traz que a experiência de choque é frequente quando a notícia da morte é abrupta, o que se relaciona com o relato de Margarida quando diz "isso é muito chocante porque tu não quer acreditar que é o teu filho ali (morto)".

\subsection{A perda do filho e o futuro que não acontecerá}

"Não se trata de saudade de alguma coisa que acabou ou pessoa que morreu. É saudade do que está aí vivo, solto e nunca deixou de existir" (Elis Regina) 
Sabemos que quando uma mulher se torna mãe, inúmeras mudanças ocorrem em sua vida, que vão para além do período de gestação e primeiros anos de vida do filho. O vínculo de mãe e filho é alimentado ao decorrer da vida e do dia a dia, gerando nessa mãe preocupações advindas da necessidade de proteger e apoiar este filho, durante todo o desenvolvimento infantil e, inclusive, na vida adulta e velhice. A preocupação da mãe passa a ser proporcionar boas condições de vida para seu filho, além de preparar e idealizar um futuro para e com este, com base nos cuidados e ensinamentos que lhe foram proporcionados ao decorrer deste vínculo (Zanatta, Pereira, \& Alves, 2017).

Bromélia traz em seu relato a sensação de frustração que acompanha a dor da perda do seu filho "perder um filho é perder todo o futuro. Perder os pais, bom, acontece, a gente perde o passado, a gente perde as nossas raízes. Mas perder um filho é perder todos os planos, é perder todo um futuro" Margarida demonstrou sua tristeza, deixando lágrimas correr pela sua face ao trazer-nos o relato "Ver as pessoas da minha idade se tornando avós e saber que nunca serei chamada de vó por um neto meu...". Nestes relatos, evidenciamos o que Filho e Lima (2017), trazem sobre os planos e projetos para aquele filho, junto com os momentos em família que foram interrompidos, causando vazio existencial neste grupo familiar.

Crisântemo, em seu relato, representa os sonhos que foram enterrados junto de seu filho "Estávamos aguardando casar, sonhando com isso, já estávamos idealizando os netinhos". Sandielly e d'Agostini (2015, p. 215) trazem que "a morte de um filho é sentida e descrita pelos pais como algo dilacerante. Perde-se o controle sobre o futuro, planos, expectativas e sonhos e desestabiliza-se a idealização de realização pessoal que esse filho estava designado a alcançar". Quando o rompimento do vínculo entre pais e filhos ocorre por morte, além de toda carga afetiva relacionada ao sofrimento que os pais precisam dar conta, ainda há a destruição da identidade paterna, pois agora são pais de um filho que morreu. Ocorrendo ainda a destruição dos sonhos que foram idealizados através do filho. Por despertar sentimentos e sensações tão complexas, o processo de luto de pais que perderam seu filho pode despertar reações incomuns, segundo Filho e Lima (2017), como relata a mãe Bromélia "Eu chorei tanto, por dez anos, todos os dias eu chorei". Neste momento Margarida complementou falando que chorou todos os dias após a morte de sua filha, até completarem nove anos de sua morte.

\subsection{Relação conjugal após a perda do filho}

De acordo com Filho e Lima (2017), perder um filho é uma experiência que impõem muitas adaptações aos pais, as quais precisam enfrentar com base em sua experiência singular, na particularidade de sua dor, são mudanças referentes à concepção de mundo e papéis que se alteram, tanto em nível individual, relação conjugal e social. A participante Crisântemo relatou sobre sua relação conjugal após a morte do filho "eu sofri ainda mais depois da morte do meu filho porque 
o meu marido queria se matar, de um jeito ou de outro, ele tentou várias formas de morrer e não conseguiu. A gente pensa às vezes para que viver ainda né!? Mas ali eu me acabei, eu fiquei velha. Meus nervos acho que nem tenho mais, de tanto me preocupar com esse homem. Até ficou internado no hospital e eu cuidei. Depois ainda nos separamos, pois ele estava no caminho do mal".

A angústia de Crisântemo foi nítida em seu relato sobre sua relação conjugal após a morte de seu único filho. As tentativas de suicídio do marido acentuaram o sofrimento de Crisântemo, que relatou também, não conseguir lembrar de muitos detalhes dos primeiros três ou quatro anos depois da morte do filho, tamanha dor que vivenciou neste período. Após todo sofrimento envolvido nesta relação conjugal, Crisântemo e seu marido decidiram se divorciar. Relatou sobre "e não deveria né! Daí que o casal deveria ficar juntos, porque Deus deu esse filho para os dois, juntos. Mas se não dá para seguir na relação, não dá! ".

Margarida comentou sobre o relato de Crisântemo, "mas isso se ouve falar muito. O que observo muito assim, é que os casais se separam, depois da perda dos filhos". Sobre seu próprio relacionamento conjugal, Margarida relatou "Principalmente nos primeiros tempos, tinha em mente que eu não ia viver mais. E assim, eu e o meu marido nos unimos muito e eu me lembro que um dia ele me abraçou e me disse: nós vamos enfrentar tudo isso juntos! ".

Ciclame é a única participante que já tinha se divorciado antes da morte da filha, mas mesmo assim, trouxe a frustração que sentiu sobre seu antigo companheiro e pai da jovem "E o pai dela, ele não quis nada das coisas. E ela (filha falecida) tinha as fotos dela, de bebê, do crescimento, da adolescência e tinha um outro álbum que era o book de fotos (de estúdio) dela. Aí eu quis dividir um álbum para cada um, mas ele não quis. Aí eu disse para ele: bom, a gente não precisa se apegar às coisas da nossa filha, sempre vai estar aqui, sempre no nosso coração. E ela tinha uma Bíblia no apartamento e então o pai dela pediu para ficar com uma Bíblia dela".

Já Bromélia relatou as dificuldades financeiras que a família estava passando e que acentuaram com a morte do filho "Sabe quando tudo, tudo desmorona? Nós estávamos com as prestações da casa todas atrasadas, o carro tinha fundido o motor, eu estava num aperto também, fechou a minha escolinha, eu precisava lecionar, dívida da casa, das lojas, cobradores, agiotas. Sabe quando ferra a tua vida, entende? "Neste relato, a participante descreve como sua vida já não estava adequada e ainda se soma a perda do filho, gerando ainda mais sofrimento e sensação de impotência frente a sua realidade.

A conjugalidade pode apresentar-se de modo a contribuir para que o casal permaneça unido após a perda do filho, de forma com que os cônjuges possam servir de apoio um ao outro nos momentos difíceis, desde que haja nesta relação confiança e lealdade possibilitando abertura de expressarem suas emoções. Porém quando o processo de luto individual interfere no luto entre 0 casal, pode haver um distanciamento, assim como outros fatores que vão desde a situação em que 
a relação conjugal estava antes da morte do filho, até a relação que cada cônjuge/ genitor tinha com o filho. É importante considerar que a morte de um filho altera a própria dinâmica familiar, assim, os cônjuges buscam reconfigurar não só a relação conjugal, assim como a relação familiar (Morelli \& Scorsolini-Comin, 2016).

\subsection{Relações sociais após a perda do filho}

Em um momento trágico, como a perda de um filho, é essencial que os pais recebam apoio emocional para que o luto possa ser vivenciado em seu complexo processo. Quando pessoas enlutadas compartilham sua experiência de dor com a sociedade onde vivem, se permite que sejam gerados conhecimentos pessoais e coletivos (Franqueira \& Magalhães, 2018). Desta forma, questionamos as participantes sobre as relações sociais experienciados após a perda do filho, onde Bromélia, após refletir um pouco, compartilhou o quanto este mesmo olhar social pode gerar uma interferência negativa "às vezes quando a gente está envolvida em um grupo social, conversando, se distraindo, vivendo... Aí chega alguém e diz: "Nossa, mas como tu está bem, tu perdeu o teu filho, mas como tu conseguiu superar bem isso né! "Nossa aí desaba o mundo quando a gente ouve essas coisas. Parece que as pessoas querem sempre te ver mal, sempre te ver chorando. $E$ quando isso não acontece, o quanto essas pessoas também julgam, porque se tu tá sentada chorando todo mundo diz: tá mas tua vida continua, precisa seguir".

Ciclame trouxe o quanto as pessoas demonstravam curiosidade para saber de detalhes da morte da filha, que ocorreu em outro município "principalmente logo no início, eu evitava de ir para rua, mas eu tinha que ir. As pessoas queriam saber das coisas, queriam ajudar, mas acabaram atrapalhando, é como se tivesse uma ferida e alguém fosse lá e passava uma faca para sangrar mesmo. E aí todo mundo perguntava, todo mundo queria saber as coisas".

Neste momento, Crisântemo compartilhou o sofrimento que a insensibilidade social the provocou, com tamanha curiosidade sobre o acidente de trânsito que vitimou o filho, trazendo ainda, sobre os boatos gerados com o objetivo de denegrir a imagem de seu filho, ela relatou "no meu caso também todo mundo pedia "já veio o resultado da perícia? Já saiu a perícia? " E isso demora para sair, demora para ter um resultado, as pessoas ficavam sempre pedindo sobre isso. E boatos foram gerados de pessoas próximas, sobre a perícia ter dado um resultado sobre droga ou consumo de bebidas. Isso me magoou muito".

Ciclame comentou sobre ter iniciado a frequentar um grupo de artesanato, logo depois da morte da filha, para tentar se ocupar e se distrair, porém não se sentiu acolhida, pois as outras pessoas que participavam a questionaram sobre os detalhes do assassinato e sobre sua reação emocional e comportamental frente a este evento traumático. Relatou que se sentiu pressionada e desconfortável, levando a desistência em participar de tal grupo.

Rev. Psicol Saúde e Debate. Jan., 2022:8(1): 138-159. 
Margarida revelou ter sido muito questionada, principalmente nos piores momentos de seu luto, após a morte da única filha, sobre ter outro filho ou adotar. Revelou "por mais que as pessoas julguem, por mais que as pessoas falem, não interessa se uma mãe tem 10 filhos. Aquele que faleceu sempre vai ser o que falta, não dá para substituir as pessoas falam: adota ou busca outro, tenta ter outro. Mas não é assim, é aquele ali que se foi, e isso dói de uma maneira que não tem como fazer sarar".

Freitas (2018) destaca que para que o enlutado possa se sentir acolhido o apoio social é de extrema importância, seja por instituições, amigos, comunidades ou parentes. A importância do acolhimento social foi trazida nas palavras de Crisântemo "ainda bem que a gente tem pessoas boas ao nosso redor, as pessoas que a gente ama, que a gente cuida. Eu particularmente, tenho um afilhado, que era afilhado do meu filho, e eu sou muito apegada a ele. E me faz bem!" Bromélia também trouxe seu relato onde teve acolhimento pelas colegas de trabalho "algo que me ajudou muito depois da morte do meu filho, foi continuar trabalhando. Eu ia no médico e pedia atestado, eu dizia "eu não aguento mais" e o doutor me dizia que eu precisava trabalhar, que eu precisava me ocupar. Eu ia dar aula e daí no meio da aula, eu saia da sala, eu precisava chorar, mas aí as professoras, as minhas colegas, vinham me abraçavam, me apoiaram e isso me ajudou bastante".

Com base nestes relatos percebemos o quanto seria benéfico para pessoas enlutadas, terem um espaço aberto e adequado que desempenhasse acolhimento sem julgamento, onde a troca de experiência e conhecimentos teria um papel importante tanto para a sociedade como para os enlutados que sofrem e merecem respeito no decorrer do seu processo de luto.

Rolim e Zandonadi (2019) trazem que o suporte social é uma ferramenta relevante para elaboração do processo de luto, podendo apresentar-se como palavras apoio, a ajuda e conforto como elementos fundamentais do processo de luto. Porém muitas vezes esta mesma sociedade dificulta o processo de luto, como vimos nesta pesquisa, pois segundo Pereira e Pires (2018) demonstrar sentimentos pode ser visto como uma expressão de fraqueza ao invés de ser considerada uma necessidade psicológica de viver a perda, situação que pode dificultar o apoio social, de amigos e até de familiares.

3.7 Relação entre a perda do filho e crenças religiosas

"A saudade eterniza a presença de quem se foi. Com o tempo esta dor se aquieta, se transforma em silêncio que espera, pelos braços da vida um dia reencontrar" (Padre Fábio de Melo)

Sendo o sofrimento um sentimento capaz de fazer com que as pessoas busquem se agarrar em algo poderoso para se confortar, conforme Almeida (2015), a dor de perder um ente querido 
pode gerar uma busca pela espiritualidade. Durante o processo de luto, o apoio espiritual pode surgir como amparo para os enlutados terem forças para ressignificar a vida após um grande sofrimento. Para Gomes (2019), as dimensões religiosas e espirituais revelam-se fundamentais na superação do luto pois além de provocarem a mudança na vida do indivíduo, permitem que a morte seja vista para além do fim definitivo do ente querido.

Durante o grupo focal fora surgindo falas sobre se apoiar em "algo maior". Aqui, as participantes não se referiam diretamente a Deus, mas sim a uma crença que relaciona que a morte não é o fim, mas uma passagem para outra dimensão. Os relatos sobre sonhos, cartas, leituras e crenças espíritas foram surgindo, demonstrando a necessidade de crer que o filho vive, ainda que seja para além desta vida. Como revelou Margarida "a gente precisa acreditar em alguma coisa, a gente precisa se apegar em alguma coisa, porque senão né, nada faz sentido! ".

Ciclame traz um relato voltado para a crença espírita "o espiritismo, serviu de apoio, de conforto nesse momento, a minha família é de criação católica, mas Deus é um só né? Eu já recebi duas cartas da minha filha através do espiritismo, tive que ir para outro município mais distante buscar uma das cartas". Margarida compartilha que sente que a filha está com ela "eu sinto a minha filha sempre comigo, sempre sinto, até aqui onde ela nunca morou, parece que ela sempre está com nós. Tem dias que eu abro a cortina, parece que ela tá vindo, é uma coisa boa que eu sinto e isso me conforta, sempre uma coisa boa comigo, sinto cheiro dela é tão bom". Através deste relato, Margarida demonstra que o vínculo com a filha que morreu, permanece, assim como a sensação de que esta lhe acompanha, apontando que o vínculo materno permaneça mesmo após a morte.

Ao ouvir Margarida, Crisântemo emocionou-se e disse "E até hoje eu vou no quarto dele ainda... e ele era muito agarrado em mim". Com este relato, a participante menciona ainda ter um cômodo na casa que pertence ao filho falecido, demonstrando assim, o vínculo com este, que é mantido, inclusive buscando o vínculo físico (apesar do filho já não estar vivo) mesmo após anos de sua morte. Crisântemo ainda traz o relato de dois sonhos que teve com seu filho, diz ter sido um sonho muito real, como se fosse uma experiência ao invés de um sonho, onde seu filho diz que está bem e que ela precisa cuidar de si, ao decorrer deste relato, lágrimas escorreram de seus olhos. Bromélia também relaciona um sonho com seu filho, onde pode abraçá-lo, comentou "isso não foi um sonho, sabe?".

Margarida comentou que recebera muitas leituras de amigos, voltados para o espiritismo "eu sempre fui a mais fraca, eu desabei, eu ia para o hospital e voltava, e quando estávamos fracos um lia para o outro, e a leitura fez muita diferença em nosso processo para reunir forças".

A participante Crisântemo não compartilhou sobre crenças religiosas, mas comentou sobre um acontecimento específico "Quando eu vou na igreja e os pastores ou os padres falam sobre a questão de plantar bons frutos, que os bons frutos crescem e que os bons frutos permanecem, isso me machuca muito, eu podia fugir, isso me parte o coração, porque eu fico pensando: tá então a 
minha semente não era boa?". Neste relato fica evidente a frustração em relação à perda do filho e percebe-se ainda, um sentimento de desesperança e revolta pela perda precoce, bem como a falta de amparo religioso vivenciado por esta mãe.

Podemos evidenciar, através dos relatos, que algumas destas mães se apoiaram na espiritualidade para suportar a dor e saudade do filho falecido, segundo Mautoni e Almeida (2015) o sofrimento causado pela morte de um filho, geram questões e reflexões descomunais, onde que a espiritualidade pode fornecer consolo e alento para este enlutado. Assim as religiões e crenças podem trazer algumas respostas de forma tranquila e serena que possam tranquilizar quem está vivenciando um elevado grau de sofrimento. Ainda segundo os autores (p.166) "Saber que o filho está com Deus, que dorme em sono profundo, que haverá um encontro futuramente, que o espírito do filho ainda está convivendo diretamente com a família são possibilidades muito apreciadas para os pais. Pode-se dizer que são alentadoras".

\subsection{O papel do Psicólogo frente ao luto materno}

Nos relatos das participantes desta pesquisa, apenas uma trouxe que teve acompanhamento psicológico. Ciclame contou ter recebido o acompanhamento através da saúde pública, o qual frequentou por determinado tempo. Bromélia mencionou não ter recebido auxílio psicológico, pois no momento da perda do seu filho estava em situação financeira difícil, não podendo pagar pelo serviço. Margarida procurou o acompanhamento psicológico com muita resistência e ao não construir vínculo transferencial com o profissional, desistiu e não procurou mais. Crisântemo diz nunca ter frequentado um profissional psicólogo. Podemos relacionar a resistência em buscar apoio psicológico com alguns fatores como o próprio julgamento social, que já foi comentado nesta pesquisa, visto que estas participantes residem em um município pequeno, fato que pode estar associado ao tabu em buscar suporte psicológico. Mas temos que considerar outras questões, mais profundas da particularidade de cada mãe enlutada, que podem incluir o próprio estigma sobre a psicologia, a negação da realidade, a dificuldade de identificar e validar seus sentimentos, além das fantasias frentes ao luto e ao próprio processo de psicoterapia, bem como a dificuldade de acesso aos atendimentos psicológicos no Sistema Único de Saúde (SUS) municipal e cuidados atinentes ao luto realizados pelas equipes de saúde do território onde estas mães vivem.

Desta forma, percebemos como ponto frágil desta pesquisa a dificuldade de acesso ao acompanhamento psicológico por parte dessas mães, particularmente considerando que o papel do profissional psicólogo frente ao luto é fundamental para o enlutado lidar com a perda de forma adaptativa, reorganizando-se frente ao mundo e a si mesmo, de forma a aprender a viver com esta perda, identificando e resolvendo conflitos e fantasias, compreendendo a relação das emoções e 
comportamentos frente a perda, em um processo onde o indivíduo possa sentir que seu sofrimento é validado, acolhido e respeitado, fortalecendo este indivíduo enlutado, para que assim, possa viver seu luto (Ramos, 2016).

O luto sendo considerado como um processo difícil, porém inevitável, Siqueira e Azevedo (2020), enfatizam que quando não elaborado pode desencadear sérios problemas na vida do indivíduo, que em muitos casos, não procura por ajuda adequada, podendo gerar assim, um problema de saúde pública. Enfatizando novamente, a necessidade de um olhar dos profissionais e gestores de saúde voltado para a abordagem terapêutica dos indivíduos enlutados, destacando mais uma vez, o quão benéfico os trabalhos voltados ao sofrimento do luto podem ser, tanto para indivíduos diretamente envolvidos, como para o próprio contexto social e familiar.

Precisamos evidenciar que o profissional de psicologia, principalmente, é quem tem conhecimentos e recursos para auxiliarem indivíduos enlutados, porém, Lopes, Martins, Carletto e Borges (2019), destacam que o os profissionais da área da saúde, recebam a capacitação adequada, para que o atendimento relacionado ao sofrimento dos indivíduos enlutados, possa ser compreensível e embasado no respeito pela dor do outro. Assim, destacamos o quanto o olhar dos profissionais de saúde é importante no acolhimento e acompanhamento das pessoas enlutadas, desde que sejam capacitados devidamente para este assunto que é envolto de tabus, sentimentos, misticismo, crenças e que deve ser conduzido de forma assertiva e cientifica.

\section{Considerações Finais}

A partir dos relatos obtidos durante a pesquisa, precisamos dar ênfase a particularidade de cada história, mesmo em situações semelhantes, onde essas mães compartilham de algumas ideias e até sentimentos, cada história é singular, cada participante trouxe sua experiência, de um momento traumático de sua vida, onde se utilizou das suas características pessoais para viver esse momento da maneira que pôde. Foi perceptível a necessidade destas participantes de um ambiente acolhedor para poderem trazer à tona sentimentos profundos e lembranças desconfortáveis, sem se sentirem julgadas ou pressionadas a falar.

Nas falas que surgiram ao decorrer do encontro, posso destacar a dor que as participantes trazem, de forma dilacerante, como descrita pelas próprias participantes, onde sentem terem perdido um pedaço de si, e as expectativas e planos para o futuro, junto com o filho que faleceu. Foi possível evidenciar que, para as participantes desta pesquisa, que perderam seu único filho, o sentimento de descrença e desesperança é mais intenso frente às participantes que possuem outros filhos, talvez por encontrarem nesses outros filhos o motivo para seguirem vivendo e lutando por dias melhores.

Rev. Psicol Saúde e Debate. Jan., 2022:8(1): 138-159. 
Com base nos relatos percebo que alguns dos papéis que estas mulheres ocupavam sofreram alterações, após sentirem a dor da morte do filho, dentre eles o de ser mãe de um filho morto. Alteração esta significativa na vida destas mulheres, que reflete no modo de se relacionar tanto com seu mundo interno, onde precisam encontrar uma maneira de lidar com a dor, quanto com seu mundo externo, onde a mudança do papel social também faz parte deste processo de ressignificações.

As relações destas mães entrevistadas com o mundo externo, teve mudanças, desde a vida conjugal até seu espaço social, que foi muito discutido como interferência negativa no processo de ressignificação da morte de seus filhos. O julgamento social apareceu muito forte no relato das quatro participantes, que trouxeram relatos de se sentirem constrangidas e situações sociais. O que evidencia o quanto a sociedade tem dificuldades para lidar com o luto, e por muitas vezes não sabendo o que dizer para a família enlutada, principalmente em situações como esta, onde a sequência natural é invertida, levando os pais a enterrem seus filhos.

Verifica-se a necessidade de refletirmos sobre o papel do psicólogo frente à situação de luto. Apenas uma das quatro mães entrevistadas procuraram por ajuda psicológica após a morte de seu filho, considerando que todas as participantes moram no mesmo município e que este situase no interior do estado do Rio Grande do Sul, podemos pensar que a saúde pública do município pode não estar sensível a tal temática, visto que as situações que levaram a morte dos jovens geram comoção local e sofrimento na comunidade, mas conhecimento por parte das equipes de saúde de tais situações de luto. Neste contexto nos perguntamos: Por que estas mulheres não foram acolhidas em seu sofrimento pelo serviço de saúde pública? Inclusive podemos lembrar que uma das mães disse que não tinha condições financeiras na época de pagar por psicoterapia, o que nos leva a pensar que ela teria desejo e poderia ter sido acolhida pela rede pública de saúde. Além disso, não podemos deixar de considerar que ainda existe resistência em buscar ajuda psicológica. Devemos refletir sobre o quanto o suporte seria positivo frente às famílias enlutadas, seja por profissionais da rede privada ou pública de saúde, que poderia até mesmo ofertar momentos grupais de reflexão e trocas de experiências, gerando acolhimento às famílias enlutadas e consequentemente apoio social.

Analisando as questões que as participantes trouxeram como positivas no enfrentamento à dor vivenciada na morte do filho, é importante apontar o papel social de familiares e amigos, principalmente os mais próximos, que serviu como apoio para estas mães enlutadas. Também é importante destacar, que durante o relato das entrevistadas, trouxeram como ferramentas de auxílio o trabalho, a leitura e o apego a crença espírita, pois esta crença possibilita que o filho permaneça vivo em outra dimensão, permitindo assim, a continuidade do vínculo com o filho morto e o sonho que um dia o encontrar novamente. 
Portanto, através desta pesquisa, buscou-se acolher estas mães e estudar as principais mudanças que o luto pela perda de um filho gerou na vida destas mulheres. Além disso, pode-se observar as principais dificuldades sociais que surgem, e identificando ainda, as estratégias utilizadas pelas mesmas para ressignificar esta dor. Pretende-se que esta pesquisa sirva como acolhimento para outras mães que vivem a angústia de ter perdido seu filho em fase adulta e que possa motivar os serviços de saúde para a construção de grupos de apoio terapêutico que aborde as principais necessidades que surgem ao longo desta experiência, além de motivar novos pesquisadores a explorarem sobre o tema que é tão genuíno e ao mesmo tempo necessário.

\section{Referências}

Almeida, T.C.S. (2015). Espiritualidade e resiliência: enfrentamento em situações de luto. Sacrilegens, v. 12, n. 1, 72-91. http://www.ufjf.br/sacrilegens/files/2016/03/12-1-7.pdf

Augras, M. (1977). Psicologia da gravidez, parto e puerpério. Arquivos Brasileiros de Psicologia Aplicada: Petrópolis.

Bowlby, J. (2004). Perda, tristeza e depressão. São Paulo: Martins Fontes

Filho, J., Lima, D. (2017). Luto parental e construção identitária: compreendendo o processo após a perda do filho. Psicologia Argumento, 35(88). Doi: https://doi.org/10.7213/psicolargum.35.88.AO02

Creswell, J.W. (2007). Projeto de pesquisa: métodos qualitativo, quantitativo e misto. Artmed: Porto Alegre.

Dsm-v. (2014). Manual diagnóstico e estatístico de transtornos mentais. Artmed: Porto Alegre.

Franqueira, A. M. R., Magalhães, A.S. (2018). Compartilhando a dor: o papel das redes sociais no luto parental. A Pesquisa Qualitativa em Psicologia Clínica. (v. 6 n. 11) 373-389. https://doi.org/10.33361/RPQ.2018.v.6.n.11.172

Freitas, J. L. de., Michel, L. H. F. (2014). A maior dor do mundo: o luto materno em uma perspectiva fenomenológica. Psicologia em Estudo [online](v. 19, n. 2) 273-283. https://doi.org/10.1590/1413-737222324010

Freitas, A. M. O. (2018). Luto de morte e suas manifestações no adulto. Revista Somanlu: Revista de Estudos Amazônicos (v. 18 n. 01), 8-21. From:

https://www.periodicos.ufam.edu.br/index.php/somanlu/article/view/4961/3965

Freud, S. (2006). Artigos sobre a metapsicologia e outros trabalhos. Imago Editora: Rio de Janeiro.

Fukumitsu, K. O. , Kovács, M. J. (2016). Especificidades sobre processo de luto frente ao suicídio. Psico (Porto Alegre) (v. 47, n. 1) 03-12. http://dx.doi.org/10.15448/1980-8623.2016.1.19651

Gallert, A. Z., Loureiro, D. G., Silva, M. R. B., Souza, R. C. (2011). Subjetividade na pesquisa qualitativa: uma aproximação da produção teórica de gonzález rey. Educação on-line (PUCRJ) (v. 8) 01-18.

From: https://www.maxwell.vrac.pucrio.br/colecao.php?strSecao=resultado\&nrSeq=18055@1 
Gomes, A. J. G. (2019). Competências profissionais e concepções religiosas dos psicólogos no acompanhamento do processo de luto. Veritati - Repositório Institucional da Universidade Católica Portuguesa. http://hdl.handle.net/10400.14/27595

Gonçalves, J. T.T. (2014). Luto parental em situações de morte inesperada: reações à perda, estratégias de coping e percepção de qualidade de vida. [Master's thesis, Universidade de Lisboa]. https://repositorio.ul.pt/bitstream/10451/18271/1/ulfpie047275_tm_tese.pdf

Kovács, M. J. (1992). Morte e desenvolvimento humano. Casa do Psicólogo: São Paulo.

Lopes, B. G., Martins, A. R., Carletto, M. R., Borges, P. K. de O. (2019). A dor de perder um filho no período perinatal: uma revisão integrativa da literatura sobre o luto materno. Revista Stricto Sensu (v. 04, n. 02) p. 29-40. https://doi.org/10.9789/21755361.rpcfo.v13.10213

Mautoni, M. A. de A. G., Almeida, T. C. S. (2015) .o luto pela morte do filho, espiritualidade e resiliência psicológica. Ces Revista, (v. 29, n. 2) 158-175. From; https://seer.cesjf.br/index.php/cesRevista/article/view/485/pdf_51

Menezes, N. R. C., Marciano, R. de P. (2019). Morte na maternidade. Perspectivas em Psicologia, (v. 23, n. 1) 176-189. From:

http://www.seer.ufu.br/index.php/perspectivasempsicologia/article/view/51148

Michel, L. H. F., Freitas, J. de L. (2019). A clínica do luto e seus critérios diagnósticos: possíveis contribuições de tatossian. Psicol. USP (v. 30) 1-9. https://doi.org/10.1590/0103-6564e180185.

Morelli, A. B., Scorsolini-Comin, F. (2016). Repercussões da morte do filho na dinâmica conjugal de casais religiosos. Temas psicol., (v. 24, n.2) 565-577. http://dx.doi.org/10.9788/TP2016.2-10

Oliveira, J. B. A. de., Lopes, R. G. da C. (2008). O processo de luto no idoso pela morte de cônjuge e filho. Psicol. Estud. Maringá, (v. 13, n. 2) p. 217-221. https://doi.org/10.1590/S141373722008000200003

Pereira, S. M., Pires, E. F. (2018). As experiências de perdas e luto na contemporaneidade: um estudo bibliográfico. Revista Educação-UNG-Ser (v. 13, n. 1) 200-217. From: evistas.ung.br/index.php/educacao/article/view/2837

Ramos, V. A. B. (2016). O processo de luto. Psicologia-Portal do Psicólogo, 1-16. From: https://www.psicologia.pt/artigos/textos/A1021.pdf

Rolim, J. A., Zandonadi, A. C. (2019). A influência da religiosidade perante o processo de luto. Revista Farol - Rolim de Moura - RO (v. 8, n. 8) 212-230. From: http://revistafarol.com.br/index.php/farol/article/view/158

Rolón, G. 2010. Palavras cruzadas - Da dor a verdade. Editora Planeta.

Sampieri, R. H.,Collado, C. F., Lucio, M. del P. B. (2013). Metodologia de Pesquisa. Penso: Porto Alegre.

Sandielly, K.S., D'agostini, C. L. F. (2015). Quando os filhos dizem adeus: a percepção sobre a morte e o processo de luto dos pais que perderam seus filhos em situação de tragédia. 
Pesquisa em psicologia - anais eletrônicos. 215-230. From: https://core.ac.uk/download/pdf/235133028.pdf

Siqueira, A. C., Azevedo, D. F. (2020). Terapia do luto: intervenções clínicas na elaboração do processo de luto. Revista Farol, Rondônia, (v. 9, n.9) 1-16, From:

http://revistafarol.com.br/index.php/farol/article/view/154

Soares, L. G., Kuchla, É., Mazza, V. de A., Soares, L. G., Ferras, M. I.R., Mattei, A. P. (2020). Mães de anjos:(re) vivenciando a morte do filho como estratégia de enfrentamento. Escola Anna Nery, (v. 24, n. 1). From: https://www.scielo.br/pdf/ean/v24n1/pt_1414-8145-ean-24e20190030.pdf

Viorst, J. (1988). Perdas necessárias. Melhoramentos: São Paulo.

Vitekpasa, D., Stelmachuk, M. S. da L. (2015). Luto Não Nominado: a Vivência do Cotidiano de Mães e Pais após a Perda de um Filho Adulto Jovem. Tuiuti: Ciência e Cultura (n. 51), 135154. From: https://seer.utp.br/index.php/h/article/view/899

Zanatta, E.; Pereira, C. R. R., Alves, A.P. (2017). A experiência da maternidade pela primeira vez: as mudanças vivenciadas no tornar-se mãe. Pesquisas e Práticas Psicossociais (v. 12, n. 3), 1-16. From: http://www.seer.ufsj.edu.br/index.php/revista_ppp/article/view/2646

Worden, J. W. (2013) Terapia no luto e na perda: um manual pra professores da saúde mental. Roca: São Paulo. 